\title{
British Journal of SPORTS MEDICINE
}

Br J Sports Med 2011;45:A6 doi:10.1136/bjsports-2011-090606.18

- ISSSMC abstracts

\section{Oral salt supplementation and long-distance exercise}

1. C Lehance1,

2. C Rodriguez de la Cruz1,

3. L Counet2,

4. L Seideil3,

5. T Bury1

\pm Author Affiliations

1. ${ }^{1}$ Department of Motricity Sciences, Liege University, Liege, Belgium

2. ${ }^{2}$ Department of Public Health, Liege University, Liege, Belgium

3. ${ }^{3}$ Department of Biostatistics, Liege University, Liege, Belgium

\section{Abstract}

During long-distance exercise, it can become difficult to continue to provide good nutrition support. The aim was to evaluate the potential of sausage "Saucisport" (water: 71\%, proteins: $17 \%$, carbohydrates: $3 \%$, fat: $6 \%$, other: $3 \%$ ) to maintain metabolic balance and performance during long-distance exercise. 10 male long-distance runners (mean \pm SD: age $34 \pm 14 \mathrm{y}$, height $177 \pm 6 \mathrm{~cm}$, weight $71 \pm 6 \mathrm{~kg}, \mathrm{VO}_{2 \max } 56 \pm 8 \mathrm{ml} / \mathrm{min} / \mathrm{kg}$ ) performed two sessions on treadmill ( $4 \mathrm{~h}$ at $65-70 \% \mathrm{VO}_{2 \max }$ ). These two exercises were separated by 10 days. Subjects were randomised to receive "standard" or oral salt supplementation. During rectangular test, different parameters were recorded every hour (T0, T1, T2, T3, T4) and $1 \mathrm{~h}$ postexercise (T5): ventilation, respiratory quotient, oxygen consumption, heart rate, insulin, glucose and free fatty acids. Analysis of respiratory and cardiovascular parameters did not show any difference between salt and sugar supplementation, although in general the values observed in sweet supplementation are slightly higher than those in salt supplementation. Evolution of insulin during the stress test was comparable in both types of supplementation. Blood glucose values were higher after $3 \mathrm{~h}(\mathrm{p}=0.036)$ and $4 \mathrm{~h}(\mathrm{p}=0.014)$ of effort under "standard" supplementation, but were not different at the end of the exercise test. Our study shows that the sausage Saucisport ${ }^{\circledR}$ does not alter the physiological parameters, metabolic balance or performance during long-distance exercise. 